\title{
A TEORIA GEOSSISTÊMICA E SUA CONTRIBUIÇÃO AOS ESTUDOS GEOGRÁFICOS E AM BIENTAIS
}

\author{
Cleide Rodrigues*
}

\begin{abstract}
Resumo: 0 estudo propõe a retomada de discussões a respeito da pertinência e aplicabilidade de antigas referências teóricas e metodológicas no âmbito da Geografia Física e da própria Geografia. Recupera parte da filogenia da teoria geossistêmica com o objetivo de articulá-la a outras referências igualmente importantes nessa área do conhecimento. Demonstra como as tentativas de síntese, objetivos dos mais perseguidos da Ciência Geográfica, constituem passos fundamentais para a aplicação desse conhecimento, seja no ensino, nas práticas de planejamento territorial e ambiental ou para fundamentar reflexões de natureza teórica. São identificados alguns caminhos que fizeram que parte desse legado tenha sido equivocadamente perdido nos estudos que se defrontam com sínteses e interdisciplinareidade, principalmente no Brasil. Identifica também a natureza das atuais dificuldades para contribuir de forma efetiva para o desenvolvimento dessa teoria e de referências assemelhadas igualmente relevantes para a construção do conhecimento geográfico do território brasileiro.
\end{abstract}

Palavras- chave: Geossistemas; Geografia Física; Teoria geográfica, Interdisciplinaridade

\section{Introdução}

Grande parte do arcabouço teórico - metodológico da Geografia Física é freqüentemente negligenciada pelos teóricos da Geografia, principalmente mediante as necessárias, porém arrasadoras, críticas ao seu pragmatismo, utilitarismo, cientificismo, entre outras tendências consideradas características. Também é verdade que a Geografia, e especialmente a Geografia Física, absorvem com rapidez as influências de contextos científicos sem contribuir ou apropriar-se dos debates na filosofia da ciência com a mesma velocidade e eficiência.

Essas duas tendências não são novas. A primeira remonta às primeiras explicitações da Geografia como ciência ideologicamente orientada, aos primeiros debates entre 0 possibilismo e o determinismo ou às primeiras elucidações das funções geopolíticas da produção do conhecimento descritivo de vastos territórios.

Apesar de antiga, essa primeira tendência foi em parte reforçada por diversos acontecimentos ocorridos ao longo de todo 0 século XX e, especialmente, a partir das décadas de 60 e 70. Dentre esses acontecimentos, é possível citar como exemplo 0 aprofundamento de determinados debates a partir do surgimento da Geografia Crítica. Com muito mais ênfase do que noutros momentos, nesse, toda a comunidade geográfica é convocada a observar e tomar consciência da possibilidade de se realizarem sérios equívocos por analogias indevidas, principalmente as transferidas no sentido Geografia Física - Geografia Humana. Passou-se a temer as transferências de categorias analíticas, e principalmente de interpretações, que pudessem produzir falsas explicações da realidade geográfica. Dentre outras posturas, todos foram convocados a assumir, de uma vez por todas que, à Geografia Física, não caberia contribuir isoladamente para a explicação dos fatos geográficos. Sob sua ótica, qualquer tentativa valorativa, interpretativa ou explicativa poderia estar fadada aos abusos do determinismo ou à criação de falsos eventos. Nas práticas acadêmicas e em nome desse necessário cuidado, não só os recursos metodológicos como também os

* Departamento de Geografia USP, C.P. 2530, 01060-0970, São Paulo (SP), Brasil 
próprios conteúdos da Geografia Física foram, de forma equivocada, descartados em estudos geográficos e, inúmeras vezes, ignorados.

Quando JOLY (1977) avalia o desenvolvimento da geomorfologia na França, ou quando GREGORY (1992) demonstra a força dessa tendência também na Geografia produzida em países de língua inglesa, passamos a ter clareza de que o problema da negligência ou do abandono da Geografia Física, reforçado nessa época, não se localiza em arranjos institucionais particulares, em escolas específicas de Geografia ou em determinados momentos e contextos científicos. Trata-se de uma tendência generalizada.

Em algumas das situações tratadas por JOLY (op. cit.), é possível verificar que nas décadas de 60 e 70, a Geografia Física francesa passa a perder espaços acadêmicos e curriculares, o que retarda seu desenvolvimento substantivo e, por conseguinte, são perdidas oportunidades preciosas para um trabalho mais reflexivo no plano epistemológico.

Esse generalizado processo de abandono da Geografia Física é acompanhado, nessa mesma época, pelo seu oposto noutros ramos científicos. Na contramão desse processo, outras ciências vêem-se com papéis reforçados para atender as demandas da então emergente temática ambiental.

A subdivisão do trabalho científico e a velocidade no desenvolvimento de técnicas de observação, análise e mensuração da realidade observados a partir da Segunda Guerra Mundial, principalmente no plano das Ciências Físicas e Biológicas, também fazem parte desse relativo isolamento a Geografia Física em relação à Geografia. Com sua subdivisão em campos progressivamente específicos e com a necessidade de serem revistos seus métodos e técnicas, a Geografia Física, numa tentativa de adaptação a essa nova realidade e às novas demandas, acaba por envolver-se em seu mundo próprio, por si só cheio de questões e dificuldades a serem enfrentadas. Isso também traz empecilhos para o necessário e cada vez mais intricado objetivo de síntese, e, obviamente, para 0 trabalho interdisciplinar.

E é assim que também podemos explicar, ao menos em parte, por que os contatos e debates entre as "duas Geografias" foram, de forma generalizada, anestesiados nessas últimas décadas.

Tratando-se de arranjos acadêmicos brasileiros, é notável como a Geografia perde oportunidades preciosas de avançar em conhecimentos de síntese do meio físico ou em abordagens integradas de questões ambientais, a pesar de encontrarmos na Geografia Física, e não nas Ciências da
Natureza exclusivamente analíticas, a maior parte dos recursos teóricos que fazem parte das referências para tais abordagens. Nas últimas décadas, nem mesmo um ambiente externo, relacionado às novas demandas da legislação ambiental, favorável ao desenvolvimento e à aplicação das referências metodológicas existentes em seus circuitos, promoveu ou reforçou seu uso e sua difusão.

Além disso, o conhecimento teórico e substantivo que, mesmo com essa relativa perda de espaço, vem sendo produzido e desenvolvido na área de Geografia Física, poderia estar sendo significativamente melhor aproveitado e apropriado pela Geografia como um todo. Na atualidade fazse necessário compreender que o processo de produção desse conhecimento nem sempre carrega, de início, ignorância a respeito dos valores subjacentes aos conteúdos selecionados e aos métodos de ponderação para qualificação ou classificação de espaços ou territórios. Nem sempre os conteúdos selecionados em estudos de Geografia Física trarão, no começo, prioridades externas ou estranhas aos interesses, por exemplo, de uma Geografia Crítica. É preciso compreender que, hoje, raramente se transferem os métodos explicativos dos fatos do mundo físico ou ambiental, ainda úteis em seu campo, para os métodos explicativos propostos para a Geografia propriamente dita.

Portanto, o momento é oportuno para que, noutro patamar qualitativo, se resgatem articulações entre a Geografia Física e a Geografia Humana.

Neste pequeno ensaio pretende-se retomar uma pequena parcela das referências teóricas básicas em Geografia Física, demonstrando-se suas potencialidades e dificuldades, tanto no que se refere à uma realização mais plena, quanto à colaboração com a Geografia em sua busca pela compreensão da totalidade. Destaca-se a teoria geossistêmica que, após aproximadamente 30 anos de proposição, pode ainda ser considerada pouco conhecida, aplicada ou testada no território brasileiro.

\section{A teoria geossistêmica: fontes de inspiração e desenvolvimento no contexto da Geografia Física.}

É razoável pensar que uma das fontes de inspiração dessa teoria, bem como de outros modelos que visam à integração do meio físico - biótico tenha sido a própria escola dos naturalistas do século XIX, cujas práticas foram disseminadas principalmente por meio das nascentes 
sociedades geográficas do século XX. Nomes como 0 de von Richthofen ou de von Humboldt, sempre lembrados na história do pensamento geográfico, também nesse caso servem para lembrar que as práticas localizadas no século XX induziram a consolidação de determinados procedimentos metodológicos, como por exemplo, a necessidade da observação e da descrição detalhada de campo.

Marcam essa fase de grandes expedições e descrições territoriais as sociedades geográficas nacionais e a criação de cátedras em Geografia. Nos primórdios do século XX, inúmeras sociedades científicas novas foram fundadas. Em 1866, somavam-se dezoito sociedades geográficas e, em 1930, cento e trinta e sete (GREGORY,1992).

As influências externas que pairavam sobre a Geografia nessa época, meados do século XIX e início do século XX, advinham da abordagem positivista. Especificamente sobre as Ciências da Natureza, alguns princípios de ordem geral tais como o uniformitarismo, a teoria evolucionista, os métodos descritivos, comparativos e as generalizações empíricas, constituíam a base do trabalho científico.

É inegável que o conhecimento geográfico gerado estava inequivocamente comprometido com empreendimentos colonizadores. Entretanto, um volumoso conhecimento territorial ou substantivo foi produzido e sistematizado, proporcionando significativo enriquecimento teórico e metodológico aos estudiosos da natureza.

A Geografia Física, mesmo sem ser assim denominada ${ }^{1}$ e mesmo sem assimilar adequada e conscientemente a abordagem positivista característica do momento, utiliza-se plenamente desses e de outros princípios e não os descarta posteriormente. Já a crítica ao positivismo lógico e às posturas deterministas impôs à Geografia como um todo e principalmente à Geografia Humana, seu afastamento desde 0 início do século XX.

Se, para a Geografia Física essa livre assimilação favoreceu, por um lado, a ausência de crítica de cunho epistemológico, por outro, significou a manutenção de certas referências metodológicas, técnicas e operacionais que ainda hoje podem ser consideradas como pertinentes e adequadas à observação sistemática e à busca de síntese (ainda que não estejamos, obviamente, falando da síntese geográfica completa).

Desse legado ainda útil é possível destacar, também como exemplo, a importância do método comparativo, um dos mais elementares do método científico e que, ainda hoje, possibilita a identificação de variáveis relevantes na explicação de fatos geográficos, principalmente aqueles de ordem física. Esse método foi passível de desenvolvimento também em função das grandes expedições realizadas no século XIX e até mesmo no século XVIII.

Os cientistas, ou exploradores, tiveram a possibilidade de observar inúmeras e contrastantes paisagens, e a busca da explicação dessa diversidade não descartou a observação, a descrição e registros minuciosos que se realizavam de forma a identificar e a integrar variáveis. Isso significa que se articulava, na medida do possível para a época, 0 conhecimento geológico com o conhecimento das formações superficiais e solos, com características florísticas, com características climáticas e até mesmo com observações sobre processos (eólicos, fluviais, glaciais, etc.). Já havia desde então preocupação com relações entre variáveis, dinâmica e principalmente com gênese, sendo estas últimas principais categorias explicativas que persistem em todo 0 campo de atuação da Geografia Física atual.

Exemplo até hoje reconhecido, pela importância dada à descrição genética e ao método comparativo, é o do pesquisador russo V. V. Dokuchaev, cujo trabalho sobre teoria zonal dos solos, publicado em 1883, passa a ser considerado 0 grande precursor da abordagem genética nas ciências do solo. As inevitáveis comparações formuladas a partir de descrições das diversas e marcantes realidades zonais do território russo contribuíram à estruturação de uma proposta de classificação que promoveu, por um lado, a superação da visão estática e geológica da gênese dos solos e, por outro, 0 desenvolvimento da identificação dos fatores de formação do solo, entre os quais o clima foi inevitavelmente considerado. A história da geomorfologia evolutiva, climática, dinâmica e de processos também fornece informações relevantes sobre a influência que determinadas escolas sofreram com o trabalho de campo em realidades distintas.

De forma geral é possível perceber que a escola dos naturalistas exerce influências inegáveis para o conjunto da Geografia Física. Entretanto, é preciso lembrar que essas e outras influências não ocorrem simultaneamente e da mesma forma. Até meados do século XX, diversas tendências metodológicas e diversas preferências de conteúdos caracterizavam escolas de Geografia Física e os intercâmbios entre elas eram pouco efetivos. Tratava-se, portanto, de um

(1) 0 termo fisiografia também era utilizado até então, mas passou a ser substituído por sua impressão e falta de clareza quanto às áreas do conhecimento que congregava (GREGORY,1992). 
desenvolvimento descontínuo e relativamente isolado do conhecimento teórico - metodológico da Geografia Física, no qual a construção da teoria geossistêmica está inserida.

A segunda lei da termodinâmica permitiu 0 desenvolvimento de uma teoria que representou uma contribuição mais imediata para a formulação da teoria geossistêmica: a Teoria Geral dos Sistemas. Proposta pelo biólogo Ludwig von Bertalanffy em 1901, visava tanto a investigação científica dos sistemas em várias ciências quanto sua aplicação tecnológica e, ainda, a própria filosofia dos sistemas, no sentido de promover a discussão desse novo paradigma científico.

Até meados do século $X X$, essa teoria permaneceu pouco difundida, mas uma série de apropriações em diversos ramos científicos ocorreu a partir de então. Ela propõe que os sistemas podem ser definidos como conjuntos de elementos com variáveis e características diversas, que mantêm relações entre si e entre o meio ambiente. A análise poderá estar voltada para a estrutura desse sistema, para seu comportamento, para as trocas de energia, limites, ambientes ou parâmetros (GREGORY, 1992).

Um dos primeiros ramos científicos a utilizá-la foi a Ecologia, com a proposição do conceito de ecossistemas (TROLL, apud GREGORY, 1992). Na Geografia, sua penetração foi muito maior na área de Geografia Física, tendo em vista que sua abordagem positivista e sua natureza preferencialmente indutiva acabaram por inibir até mesmo a utilização de suas idéias centrais na Geografia Humana.

Dela surgiram, para a Geografia Física, diversas propostas de modelos conceituais, morfológicos, de classificação dos sistemas, incluindo-se os naturais (sistemas abertos). A própria noção de paisagem em Geografia Física, apesar de ter sofrido inúmeras remodelações e adquirido diversas concepções, tem como suporte lógico a teoria geral dos sistemas. A abordagem ecodinâmica de TRICART (1977), ou os próprios esquemas de classificação propostos por SOTCHAVA $(1977,1978)$ e por BERTRAND (1972), inclui-se nessa lista, assim como os preceitos de HACK(1960) na Geomorfologia, quando aprofunda a idéia de equilíbrio na natureza e da existência de ajustes recíprocos entre sistemas, subsistemas e entre suas variáveis.

A classificação da teoria geral dos sistemas como pertencente ao positivismo lógico e a consideração de sua tendência ao indutivismo não impediram interpretações diferentes a seu respeito. TRICART (1980), um dos grandes estudiosos de Geografia Física e de Geomorfologia, chega a demonstrar níveis de compatibilização dessa teoria com a lógica dialética, num artigo em que se preocupa com a elucidação das funções do trabalho de campo na dialética da Geografia. Essa aparente incongruência serve, ao menos, para se perceber que muito trabalho está por ser realizado no plano metodológico e que essa teoria necessitaria ser rediscutida para, de fato, ser aplicada ou aproveitada em estudos geográficos.

Evitada pela Geografia Humana, a teoria dos sistemas persiste até hoje como idéia precursora de uma série de referências ainda relevantes em Geografia Física. Desde a fase em que se inicia a valorização da mensuração, a incorporação definitiva da dimensão temporal, adotam-se modelagens e ampliam-se as experimentações e não se abandonam conceitos e referências dela originados.

Nota-se, então, que o conhecimento em geral, e nesse caso o conhecimento teórico - metodológico da Geografia Física, observou percursos não lineares, não necessariamente cronológicos, e que as idas e vindas estiveram sempre presentes.

No caso específico da Geografia Física e da teoria dos geossistemas, houve também empecilhos de ordem cultural e política para uma maior disseminação do conhecimento, dentre os quais podemos anotar, como exemplo, as barreiras da língua, que retardam o conhecimento da escola russa e que explicam, em parte, a tendência a uma autofagia em países anglo - saxões. Também devem ser lembrados como fatores que retardam e inibem a disseminação a aplicação e - aperfeiçoamento da Geografia Física, a supremacia generalizada da Geografia Humana em diversos contextos institucionais.

\section{A teoria geossistêmica: da proposição inicial à utilização no Brasil}

Para compreender os elementos básicos dessa proposição, é preciso reafirmar que, a teoria geossistêmica faz parte de um conjunto de tentativas ou de formulações teórico - metodológicas da Geografia Física, surgidas em função da necessidade de a Geografia lidar com os princípios de interdisciplinaridade, síntese, com a abordagem multiescalar e com a dinâmica, fundamentalmente, incluindo-se prognoses a respeito desta última.

Apesar ter sido formulada pela escola russa, por meio de V.B. Sotchava, que propõe o conceito e dele se utiliza de forma pioneira num estudo publicado em 1960, a teoria foi difundida no mundo ocidental pela escola francesa e por 
iniciativa de G. Bertrand, na mesma década, em 1968. No Brasil, são os periódicos do extinto Instituto de Geografia da Universidade de São Paulo que difundem inicialmente a proposta, de início com o número 13 dos Cadernos de Ciências da Terra, que publica o texto de BERTRAND (1972) e, posteriormente, com a tradução dos artigos de SOTCHAVA $(1977,1978)$ e com os números 14 e 16 dos cadernos Biogeografia e Métodos em Questão.

A possibilidade de gestão territorial sem 0 entrave da propriedade privada talvez também explique 0 surgimento e difusão dessa teoria na antiga URSS, tendo em vista que se promove o reconhecimento de unidades espaciais com características elementares, relacionais e dinâmicas, semelhantes entre si, mesmo incluindo-se 0 antrópico. Isso significa que possibilita a discriminação de unidades operacionais de planejamento, sejam quais forem as possibilidades de valorização política ou econômica dessas diversas unidades. Até o momento do reconhecimento das características e da delimitação espacial dessas unidades operacionais de planejamento, posturas valorativas calcadas em ideologia, entre outras, podem ser, em parte, exorcizadas do processo.

Uma colocação básica a respeito dos geossistemas é feita por SOTCHAVA (1977) logo de início. Chama a atenção para 0 fato de que os geossistemas, embora sejam considerados "fenômenos naturais", devem ser estudados à luz dos fatores econômicos e sociais que influenciam sua estrutura. Os geossistemas podem refletir parâmetros sociais e econômicos que influenciam importantes conexões em seu interior. Essas influências antropogênicas podem representar o estado diverso do geossistema em relação ao seu estado original. Esse estado derivado muitas vezes pode ser mantido por meio de outras intervenções técnicas, também passíveis de reconhecimento. Acrescenta que, apesar dos fatores sócio - econômicos modificarem um geossistema, "a noção sobre esse último não pode abranger a do sistema territorial industrial" (SOTCHAVA, 1977), o que não exclui a possibilidade ou a existência de "sistemas totais que representem sistemas geográficos, econômicos, sociais e técnicos" (SOTCHAVA, op. cit.). Essas afirmações explicitam 0 nível de síntese, no qual se pretendia trabalhar através da consideração dessa teoria e parecem revelar que, para 0 autor, a Geografia não caberia integralmente na abordagem.

Apenas depois desse parênteses, é que se pode apresentar sumariamente os princípios básicos de sua teoria. Um dos primeiros é a consideração da natureza como sistemas dinâmicos abertos e hierarquicamente organizados, passíveis de delimitação ou de serem circunscritos espacialmente em sua tridimensionalidade. Esse princípio vem carregado de todos os derivativos da teoria geral dos sistemas, dentre os quais se destaca o da articulação entre os sistemas abertos (variáveis extrínsecas) e da interdependência de suas variáveis intrínsecas (identificandose também internamente as rotas, trocas de matéria, energia e ciclos). Coloca-se que o geossistema não se subdivide infinitamente posto que depende de uma organização geográfica.

Um outro tipo de princípio básico é o bilateral, ou dual, dos geossistemas, em que se analisa, por um lado, a estrutura homogênea que caracterizaria 0 geômero e, por outro, as qualidades integrativas dos geossistemas, que caracterizaria o geócoro .

Uma outra noção implícita é a noção de dinâmica, pela qual é possível classificar os geossistemas de acordo com seu estado ou estados sucessivos, assim como é possível assumir ou propor hipóteses sobre sua dinâmica futura, característica fundamental para a aplicação ou para o planejamento. 0 caráter preditivo da proposta é um dos principais pontos de apoio de sua aplicabilidade, 0 que permite identificar a direção ou balanço de processos, inclusive por incorporar o fator antrópico.

Como orientação para a sistematização, propõe-se a modelagem, que, idealmente, deverá ser subsidiada pela mensuração direta (monitoramentos e experimentações) das trocas, circuitos, balanços de matéria e energia nos sistemas e subsistemas. BERTRAND (1972) explicita melhor a idéia dessa subdivisão, quando propõe seu esquema taxonômico que inclui e posiciona as unidades inferiores, dentre as quais figuram o "geossistema", o "geofácies" e o "geótopo".

Outra recomendação basilar para a delimitação dos geossistemas é que se deve renunciar a determinar as unidades sintéticas pela justaposição de características reconhecidas pela análise, como, por exemplo, defini-los por justaposição de classificações pedológicas, geológicas, fitogeográficas, climatológicas e geomorfológicas, que levariam, em última instância, a um mosaico sem relação com os mecanismos que estão em funcionamento em cada porção espacial ou com os balanços e direções dos processos.

Para o sistema taxonômico, BERTRAND (1972) por sua vez, define que a classificação deva ser proposta em função da escala temporo-espacial. Haveria unidades superiores, compatíveis com as "zonas", "domínios", ou "regiões naturais" 
e unidades progressivamente inferiores, que definiriam os "geossistemas", "geofácies" e os "geótopos". Essa colocação, apesar de referir-se à classificação e não à identificação dos geossistemas propriamente dita, faz parte do processo de reconhecimento, já que auxilia no dimensionamento temporo-espacial das unidades espaciais, as quais também se articulam.

BERTRAND(1972) reafirma a importância da identificação dos geossistemas, por se situarem na 4a 5a ou 6a grandezas temporo - espaciais de TRICART \& CAILLEUX (1956), escala esta mais compatível com a humana, em que a dinâmica desses geossistemas, modificada ou não, poderia expressar a dinâmica social.

Outras considerações poderiam ser formuladas com 0 intuito de explicitar o quadro de referências para aplicação da proposta, como por exemplo as possibilidades e as dificuldades em se incluir 0 antrópico para se avaliar a dinâmica de um geossistema e a direção de seus processos/mecanismos, tal como alerta MONTEIRO (2000).

Colocaríamos, ainda, a fase de representação dos geossistemas, etapa considerada fundamental para sua explicitação. Segundo os autores da proposta, esta seria realizada, por exemplo, por organogramas representativos de geômeros, ou de outros tipos de representação, tais como os perfís transversais. Nesse particular, os estudos de M ONTEIRO (1982, 1995, 2000) demonstram a diversidade das possibilidades. Em sua recente publicação, apresenta 0 tipo de aperfeiçoamento que seus estudos promoveram em relação à representação dos geossistemas, incluindo-se aí a dimensão temporal.

A difusão, apropriação e aplicação dessa teoria no Brasil apresenta os mesmos tipos de dificuldades apontadas anteriormente. Não são realizados esforços em conjunto para sua compreensão e aplicação no seio da Geografia.

Foi fundamentalmente por iniciativa individual do Prof. Dr. Carlos Augusto de Figueiredo M onteiro, na época docente do Departamento de Geografia da USP, que a experiência de aplicação da teoria pôde ser levada adiante. É por sua iniciativa que se realizam as principais, senão únicas, experiências de aplicação e de desenvolvimento da proposta no Brasil $^{2}$. Certos contextos institucionais particulares também funcionaram como importantes pontos de apoio para as empreitadas (M ONTEIRO, 2000).

Foram três as principais áreas de estudo e dois os contextos institucionais que permitiram levar adiante a aplicação da proposta de Sotchava no Brasil nos estudos realizados pelo Professor Monteiro. Além de utilizá-la como referencial teórico, ele pôde testá-la, incrementá-la e adaptá-la a algumas situações particulares de nosso território e ao próprio conhecimento territorial disponível.

No início da década de 80, a região de Ribeirão Preto, no Estado de São Paulo, foi objeto de estudo, no qual se aplicou a teoria, em projeto acadêmico com auxílio financeiro da FAPESP. Outras oportunidades surgiram na Secretaria de Planejamento, Ciência e Tecnologia do Estado da Bahia, onde o Prof. Monteiro realizou trabalhos de consultoria no final da década de 1970 e na seguinte. Essas pesquisas iniciaram-se com estudos na região central do Estado da Bahia e prosseguiram no Recôncavo Baiano.

O contexto da época em escolas de Geografia brasileiras tendia a classificar essas tentativas de síntese como uma abordagem geográfica fragmentária e parcial, tendo em vista a consideração do fator humano ou antrópico como um elemento a mais dos geossistemas a serem identificados, e não como fator social latu sensu, considerado como preponderante e explicativo da Geografia. Afirmações como essa impediam que se vislumbrassem possibilidades diferenciadas de análises e sínteses que a proposta representava.

Considero que os promotores dessa crítica poderiam têla realizado de forma a permitir 0 aprofundamento do debate científico, pois o fato de isso não ter sido realizado dificultou, por um lado, o entendimento da natureza dessa crítica e, por outro, 0 entendimento da validade e relevância da utilização da referida proposta.

Atualmente é possível considerar que a proposta de SOTCHAVA (1978), concretizada no Brasil nesses estudos de MONTEIRO (1982, 2000), seja uma das perspectivas das mais necessárias para a compreensão e valorização da dinâmica dos ambientes. Sem esse tipo de tentativa, haverá ausência de perspectivas em que se avaliam os graus de mudança ou de derivação que a interferência antrópica, em seu somatório temporo-espacial possa significar. Trata-se, portanto, de perspectiva das mais necessárias para a compreensão da história das sociedades em sua relação dialética com a natureza. Mesmo não se tratando da única perspectiva que teria essa possibilidade de apropriação para leituras geográficas mais amplas, permanece sendo uma das mais fundamentais.

(2) Na mesma época em que esse artigo era sistematizado o autor publicou Geossistemas, a história de uma procura (M ONTEIRO,2000), em que a problemática da aplicação, representação e divulgação da proposta teórica no terrirório brasileiro é amplamente caracterizada e contextualizada. 


\section{Possibilidades e limites}

Essas colocações sumárias, que pretendem subsidiar a realização de uma avaliação da contribuição da teoria geossistêmica aos estudos geográficos e ambientais, remetem também a avaliações de outras referências. Seria preferível realizar avaliações em conjunto com proposições similares, igualmente respaldadas na teoria geral dos sistemas. Entre elas, anoto como fundamentais, a proposta da abordagem morfodinâmica de TRICART (1977) ou a abordagem ecogeográfica de TRICART \& KILLIAN (1979). Essas abordagens, muitas vezes sem serem totalmente compreendidas, vem subsidiando uma série de avaliações ambientais no Brasil, na medida em que também possibilitam a identificação de unidades territoriais com dinâmicas semelhantes, passíveis de classificações diversas em processos de planejamento territorial (exemplos: fragilidade do meio físico, potencialidade para suportar obras de engenharia, etc.) e de utilização em instrumentos de gestão ambiental. Descartaria para esta avaliação de conjunto a avaliação, no conjunto, da proposta dos australianos com sua landsystem analysis, tendo em vista não estar orientada segundo os mesmos preceitos da teoria geossistêmica ou da morfodinâmica ou ecodinâmica de TRICART (1977).

Todas essas abordagens representam possibilidades de cumprir alguns dos diversos objetivos da Geografia Física, sendo que, alguns deles coincidem com os da própria Geografia.

As persistentes dificuldades para uma efetiva e disseminada implementação dessas proposições no território brasileiro acentuam o caráter ainda eminentemente teórico dessas propostas. Permanecem pouco desenvolvidas não só pelas poucas oportunidades de aplicação, mas também porque seus avanços estariam na dependência de uma maior articulação com trabalhos de campo em escalas compatíveis ou com experimentações e monitoramentos padronizados e dimensionados para esses objetivos, tal como se pretende pelas recentes proposições dos geoindicadores (COLTRINARI \& M CCALL, 1996).

Contudo, as possibilidades de aplicação das propostas merecem ser destacadas no que se refere aos objetivos geográficos. Essa aplicabilidade estaria vinculada principalmente aos objetivos relativos ao ensino de Geografia e aos de planejamento e gestão físico - territorial (ou ambiental).

Dentro da Geografia Escolar, a Geografia Física poderia trabalhar com sínteses respaldadas nesse tipo de esquemas teóricos, obviamente enriquecidos por trabalhos substantivos mais numerosos, balizados por experimentações e monitoramentos (ROUGERIE \& BEROUTCHACHVILI, 1991). Isso possibilitaria, entre outras coisas, maior consonância com 0 atual grau de derivação do meio físico, acessando - se a explicação, a gênese, as causas de os lugares se apresentarem como se apresentam na atualidade.

Com a utilização dessas abordagens seria possível trabalhar com a perspectiva genética e dinâmica em Geografia Física, uma tarefa a ser desenvolvida em todos os seus níveis de ensino. Na Geografia Escolar esse conhecimento ainda é transmitido com ênfase nas descrições e continua desarticulado do conjunto da Geografia.

Esquemas como os da teoria geossistêmica, assim como a abordagem ecodinâmica ou morfodinâmica de TRICART (1977) são apenas utilizados em pesquisas acadêmicas; seu melhor aproveitamento necessitaria, em primeiro lugar, de reconhecimento espacial de Cartografia, associados à pesquisa básica inter e intradisciplinar, fato que não ocorre de forma sistemática no caso brasileiro. Além disso, careceríamos de articulações institucionais em projetos dessa envergadura, para que tivéssemos reconhecimento territorial básico.

Assim é que as possibilidades de montagem de projetos dessa natureza acaba por tornar-se conjuntural e por vezes de iniciativa particular, conforme atesta MONTEIRO (2000).

0 conhecimento territorial falho e desarticulado, bem como a ampliação do desconhecimento teórico metodológico na área de Geografia Física acentuam a precariedade das formas de sistematização e de síntese tão necessárias ao ensino.

Com relação aos objetivos de planejamento ambiental, sem entrar no mérito dos valores e dos aspectos ideológicos dessa esfera de atuação da Geografia, as mesmas dificuldades se impõem, como é o caso da falta de conhecimento físico territorial básico do nosso território, compatível com a escala dos geossistemas, conforme afirmado anteriormente. Além dessas dificuldades, teríamos as dificuldades inerentes à própria complexidade das propostas geossistêmicas e morfodinâmicas e seu próprio desconhecimento.

Uma das principais saídas para trabalhar ou identificar unidades de planejamento físico - territorial nas experiências brasileiras, tem sido a abordagem morfodinâmica de TRICART ( 1977), "prima-irmã" da teoria dos geossistemas. Assim, com a teoria dos geossistemas, a abordagem morfodinâmica possibilita a delimitação espacial de unidades cujos processos 
atuais podem ser considerados semelhantes. Por isso é possível classificar essas unidades quanto à sua estabilidade (formas e processos), singularidade e grau de recorrência (diversidade ambiental), fragilidade ou vulnerabilidade no que se refere às interferências antrópicas, entre outras discriminações úteis na esfera do planejamento e gestão territorial característicos.

Ainda que o grau de reconhecimento territorial seja falho e que isso obrigue a se trabalhar com alto nível de inferência, um conhecimento teórico - metodológico substancial em Geografia Física possibilitaria a realização de prognoses ou hipóteses a respeito da ocorrência e localização de futuros processos com maior probabilidade de acertos.

Se conseguirmos esse conhecimento territorial aliado ao conhecimento teórico, as hipóteses ficarão ainda mais fortalecidas. Obtendo-se hipóteses consistentes a respeito da dinâmica atual dessas unidades (geossistemas inclusive), a prognose pode ser viabilizada com maior responsabilidade. Assim é que se torna possível prognosticar várias situações a respeito de interferências das mais diversas, como por exemplo de: usinas hidrelétricas, linhas de transmissão de energia, rodovias, hidrovias, núcleos urbanos, sistemas de saneamento, entre outros.

Essa possibilidade, a de formulação de hipóteses mais consistentes a respeito de processos e balanços futuros, é condição indispensável ao planejamento físico - territorial, seja qual for a apropriação ou direção político- econômica a ser seguida.

Infelizmente, as hipóteses formuladas nesse âmbito são pouco fundamentadas em orientações teórico metodológicas consistentes e tampouco servem para fazer sua crítica, pois, no geral, esses esquemas sequer são conhecidos pela maioria dos profissionais que têm a possibilidade de opinar tecnicamente sobre intervenções físico - territoriais.

Outro agravante é o fato desses levantamentos realizados ao sabor dos projetos, na sua maioria desarticulados, ficarem confinados nas diversas empresas públicas e privadas e, por isso, inviabilizarem a reformulação ou discussão a respeito dos esquemas de síntese propostos na Geografia Física, como é o caso da teoria geossistêmica de SOTCHAVA (1977) e da abordagem morfodinâmica e ecodinâmica de TRICART (1977). 
RODRIGUES, C. (2001) Geosystems theory and its contribution to geographical and environmental studies. Revista do Departamento de Geografia, n.14, p. 69-77.

\begin{abstract}
This study suggests discussions to get back Physical Geography theoretical and methodological references for its own development and application. It identifies Geosystems Theory origin and connects it to other similar and important references. It demonstrates how the synthesis and interdisciplinarity goals can be obtained by using these references and promotes their application in Geography teaching and environmental planning. It also identifies some reasons of the loss of this theoretical legacy as well as the difficulties for the development of this theory in Brazil.
\end{abstract}

Key words: Physical Geography; Geosystems; Theoretical geography

Recebido em 25 de setembro de 2000, aceito em 11 de abril de 2001.

\section{Referências bibliográficas}

BERTRAND, G. (1972) Paisagem e Geografia Física global: esboço metodológico. São Paulo, Instituto de Geografia USP. 27 p. (Cadernos de Ciências da Terra, 13)

COLTRINARI, L.; MCCALL, G.J. (1995) Geoindicadores: Ciências da Terra e mudanças ambientais. Revista do Departamento de Geografia, n.9. p. 2-11.

GREGORY, K. J. (1992) A natureza da Geografia Física. Rio de Janeiro, Bertrand Brasil. 367p.

HACK,J. T. (1960) Interpretation of erosional topography in humid temperate regions. American J ournal of Science, n.258, p.80-97.

JOLY, F. (1977) Point de vue sur la géomorphologie. Annales de Géographie, n.407, p.522-541.

M ONTEIRO, C. A. F. (1982) The environmental quality in the Ribeirão Preto region-SP: an attempt. Latin American Regional Conference Brazil/ IGU - CEP.

M ONTEIRO, C. A. F. (1995) Os geossistemas como elemento de integração na íntese geográfica e fator de promoção interdisciplinar na compreensão do ambiente. Aula Inaugural. Florianópolis, UFSC.[não publicado]

M ONTEIRO, C.A.F. (2000) Geossistemas: a história de uma procura. Org. e rev. Y.T. Rocha, J. L. S. Ross, F. Cavalheiro, L. Coltrinari. São Paulo, Contexto/Geousp. 127p. (Novas abordagens, 3).
RODRIGUES, C. (1997) Geomorfologia aplicada. Avaliação de instrumentos de planejamento ambiental e físicoterritorial em experiências brasileiras. São Paulo, 2 v. (Tese - Doutorado) - Faculdade de Filosofia, Letras e Ciências Humanas, Universidade de São Paulo.

ROUGERIE, G. ; BEROUTCHACHVILI, N. (1991) Geosystèmes et paysages: bilan et méthodes. Paris, Armand Colin.

SOTCHAVA, V. B. (1978) Por uma teoria de classificação de geossistemas da vida terrestre. São Paulo, Instituto de Geografia USP. 23 p. (Biogeografia, 14).

SOTCHAVA, V. B. (1977) 0 estudo de geossistemas. São Paulo, Instituto de Geografia USP. 51 p.(Métodos em Questão, 16).

TRICART, J. (1977) Ecodinâmica. Rio de J aneiro IBGE/SUPREN. $91 \mathrm{p}$

TRICART, J. (1980) 0 campo na dialética da Geografia. In: GUSM ÃO PINTO, J. M. (ed.) Reflexões sobre a Geografia. São Paulo, AGB. p. 97-119.

TRICART, J.; KILLIAN, J. (1979) L'écogeographie et I'amènagement du milieu naturel. Paris, François Maspero. 326p. 